\title{
Recent patents in nucleic acid sequencing and synthesis
}

\begin{tabular}{|c|c|c|c|c|c|}
\hline Patent \# & Subject & Assignee & Author & $\begin{array}{l}\text { Priority } \\
\text { application } \\
\text { date }\end{array}$ & $\begin{array}{c}\text { Publication } \\
\text { date }\end{array}$ \\
\hline WO 200151661 & $\begin{array}{l}\text { Amplifying nucleic acids in a sample for typing a pathogen and } \\
\text { determining the genetic profile of cells; comprises subjecting } \\
\text { the sample to first andsecond nucleic acid amplification using } \\
\text { a set of primers having 3-8 bases. }\end{array}$ & $\begin{array}{l}\text { Amsterdam } \\
\text { Support } \\
\text { Diagnostics } \\
\text { (Amsterdam, } \\
\text { The Netherlands) }\end{array}$ & $\begin{array}{l}\text { Dekker J, } \\
\text { Maas J, } \\
\text { van der Kuyl AC, } \\
\text { van Gemen B, } \\
\text { Zhang J }\end{array}$ & $1 / 13 / 2000$ & 7/19/2001 \\
\hline WO 200149880 & $\begin{array}{l}\text { Nucleic acid primers with specified base contents in different } \\
\text { regions; useful for primer-dependent nucleic acid synthesis } \\
\text { and amplification, particularly under isothermal conditions. }\end{array}$ & $\begin{array}{l}\text { Qiagen GmbH } \\
\text { (Hilden, } \\
\text { Germany) }\end{array}$ & $\begin{array}{l}\text { Korfhage C, } \\
\text { Oelmueller U }\end{array}$ & 12/30/1999 & $7 / 12 / 2001$ \\
\hline WO 200147638 & $\begin{array}{l}\text { A method for performing the steps of nucleic acid template } \\
\text { purification, a thermocycling reaction, and purification of the } \\
\text { products of the thermocycling reaction, characterized in that } \\
\text { the steps take place sequentially in a microfluidic disk. }\end{array}$ & $\begin{array}{l}\text { Gyros AB } \\
\text { (Uppsala, } \\
\text { Sweden) }\end{array}$ & $\begin{array}{l}\text { Andersson PX, } \\
\text { Tooke NE }\end{array}$ & $5 / 12 / 2000$ & $7 / 5 / 2001$ \\
\hline WO 200142501 & $\begin{array}{l}\text { Immobilizing nucleic acid in solution onto an unmodified } \\
\text { glass and silicon surface; useful for producing nucleic acid } \\
\text { chips and microarrays for solid-phase hybridization } \\
\text { techniques such as monitoring gene expression, poly- } \\
\text { morphism analysis, disease screening and diagnostics, } \\
\text { nucleic acid sequencing, and genome analysis. }\end{array}$ & $\begin{array}{l}\text { Karolinska } \\
\text { Innovations } \\
\text { (Stockholm, } \\
\text { Sweden) }\end{array}$ & $\begin{array}{l}\text { Kumar A, } \\
\text { Liang Z }\end{array}$ & 12/10/1999 & $6 / 14 / 2001$ \\
\hline WO 200138575 & $\begin{array}{l}\text { Preparing a sample containing biomolecule analytes and } \\
\text { macrobiomolecules; comprises mixing the sample with a } \\
\text { reagent containing branched polymer; useful for capillary } \\
\text { electrophoretic separation of biomolecule analytes, } \\
\text { particularly for DNA-related applications such as } \\
\text { sequencing and fragment analysis. }\end{array}$ & $\begin{array}{l}\text { Beckman } \\
\text { Coulter } \\
\text { (Fullerton, } \\
\text { CA) }\end{array}$ & $\begin{array}{l}\text { Huang T, } \\
\text { Keys DA, } \\
\text { Ratnayake CK, } \\
\text { Reddy MP }\end{array}$ & 11/23/1999 & $5 / 31 / 2001$ \\
\hline US 6238862 & $\begin{array}{l}\text { A process for optimizing the production, storage, and } \\
\text { use of oligonucleotide arrays produced by spatially directed } \\
\text { oligonucleotide synthesis, and in particular, light-directed } \\
\text { oligonucleotide synthesis. The method is also useful for } \\
\text { testing arrays produced under a variety of conditions used } \\
\text { in the preparation of substrates. }\end{array}$ & $\begin{array}{l}\text { Affymetrix } \\
\text { (Santa Clara, } \\
\text { CA) }\end{array}$ & $\begin{array}{l}\text { Barone AD, } \\
\text { Caviani Pease AM, } \\
\text { Chee M, } \\
\text { Diggelmann M, } \\
\text { Lockhart DJ, } \\
\text { McGall G }\end{array}$ & 9/18/1995 & $5 / 29 / 2001$ \\
\hline US 6235471 & $\begin{array}{l}\text { Sequencing a target nucleic acid; comprises use of a } \\
\text { microfluidic device for target-dependent polymerization of } \\
\text { dNTPs; useful in screening chemical or biological libraries, } \\
\text { amplifying nucleic acids, and detecting variations in } \\
\text { nucleic acid sequences. }\end{array}$ & $\begin{array}{l}\text { Caliper } \\
\text { Technologies } \\
\text { (Mountain } \\
\text { View, CA) }\end{array}$ & $\begin{array}{l}\text { Bousse LJ, } \\
\text { Knapp M, } \\
\text { Kopf-Sill AR, } \\
\text { Parce JW }\end{array}$ & 4/3/1988 & $5 / 22 / 2001$ \\
\hline WO 200132783 & $\begin{array}{l}\text { Water-soluble rhodamine dye compounds, energy transfer } \\
\text { dye pairs, and conjugates; can be used to fluorescently label } \\
\text { proteins, antibodies, receptors, nucleic acids, carbohydrates, } \\
\text { drugs, metabolites, substrates, microspheres, or liposomes for } \\
\text { use in assays involving staining of cells, protein binding, } \\
\text { and analysis of nucleic acids, such as hybridization assays } \\
\text { and nucleic acid sequencing. }\end{array}$ & $\begin{array}{l}\text { Applera } \\
\text { (Norwalk, } \\
\text { CT); PE Corp. }\end{array}$ & $\begin{array}{l}\text { Graham RJ, } \\
\text { Lee LG, } \\
\text { Lu L, } \\
\text { Swartzman E, } \\
\text { Werner WE }\end{array}$ & 9/14/2000 & $5 / 10 / 2001$ \\
\hline WO 200119841 & $\begin{array}{l}\text { Charge-modified nucleic acid terminators that result in } \\
\text { improved sequence data and allow for direct loading of } \\
\text { nucleic acid sequencing reaction onto separating media. }\end{array}$ & $\begin{array}{l}\text { Amersham } \\
\text { Pharmacia } \\
\text { Biotech } \\
\text { (Piscataway, } \\
\text { NJ) }\end{array}$ & $\begin{array}{l}\text { Bull M, } \\
\text { Finn P, } \\
\text { Flick P, } \\
\text { Kumar S, } \\
\text { Nampalli S, } \\
\text { Nelson J }\end{array}$ & 9/17/1999 & 3/22/2001 \\
\hline US 6200755 & $\begin{array}{l}\text { An assay device for nucleic acid hybridization assays } \\
\text { that has a solid support substrate, a cleavable signal } \\
\text { element comprising a signal-responsive moiety and } \\
\text { cleavable spacer, and anchoring units that bind the analyte. }\end{array}$ & $\begin{array}{l}\text { Burstein } \\
\text { Technologies } \\
\text { (Irvine, CA) }\end{array}$ & Virtanen J & 7/21/1998 & 3/13/2001 \\
\hline
\end{tabular}

Source: Derwent Information, Alexandria, VA. The status of each application is slightly different from country to country. For further details, contact Derwent Information, 1725 Duke Street, Suite 250, Alexandria, VA 22314. Tel: 1 (800) DERWENT (info@derwent.com). 